\title{
Transdifferentiation of Adipose Derived Stem Cells into Neural Stem/Progenitor Cells by
} Neurosphere Cultivation Assay

\author{
Elahe Barfi $^{1}$, Taghi Tirraihi ${ }^{2 *}$, Shahram Darabi ${ }^{3}$
}

${ }^{1}$ Department of Anatomical Sciences, School of Medical Sciences, Tarbiat Modares University, Tehran, Iran.

${ }^{2}$ Shefa Neuroscience Research Center, Khatam-al-Anbia Hospital, Tehran, Iran.

${ }^{3}$ Qazvin University of Medical Science, School of Medicine, Gazvin, Iran.

\section{ABSTRACT}

ntroduction: Adipose derived stem cells (ADSCs) have the potency to differentiate into the neuron and glial cells. One of the ways to make a large number of neural stem/progenitor cells (NS/PCs) from ADSCs is the usage of neurosphere cultivation. In this procedure, ADSCs proliferate under certain conditions continuously and make multipotent undifferentiated colonies named neurosphere that can differentiate to NS/PCs. Materials and Methods: In the current study, adipose stem cells isolated from rat inguinal and pararenal regions. Then these cells differentiated to the NS/PCs using indirect differentiation method (neurosphere culture). Adipose derived stem cells, neurosphere and NS/ PCs were evaluated using immunocytochemistry and RT-PCR techniques. Results: The results indicated ADSCs were immunoreactive to CD90, CD29, CD49d, CD44, CD105 and CD99 without any immunoreactivity for CD106 and CD31. In addition, these cells expressed the genes of Nanog, Oct4 and Sox2. Both of Neurosphere and NS/PCs were immunoreactive to Nestin, NF-68 and NF-200 and also were able to express Nanog, Sox2, NeuroD1, Oct4, Musashi1 and Nestin genes. However, these cells were unable to express MBP gene. Conclusion: It seems that indirect differentiation is effective for differentiate ADSCs into NS/PCs.

\section{Key words:}

1. Adipose Tissue

2. Neurons

3. Neural Stem Cells

4. Neuroglia

* Corresponding Author: Taghi Tirraihi

E-mail: takialtr@modares.ac.ir 


\section{تمايز سلول هاى بنيادى مشتق از بافت جربى به سلول هاى بنيادى /ييش ساز عصبى با استفاده از روش كشت نوروسفر}

$$
\text { الهه برفى'، تقى طريحى "ا:، شهرام دارابى }
$$

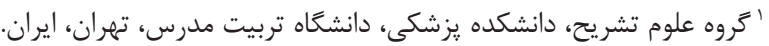

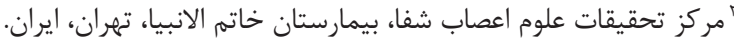

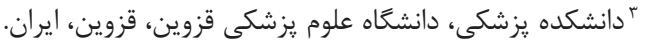

كليد وازه ها:

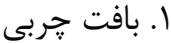

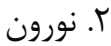

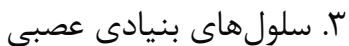

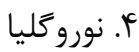

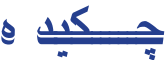

مقدمه: سلول هاى بنيادى مشتق از بافت جربى قادرند به سلول هاى عصبى و كليالى تمايز يابند.

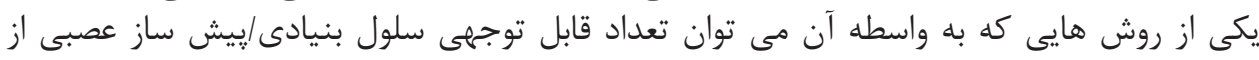

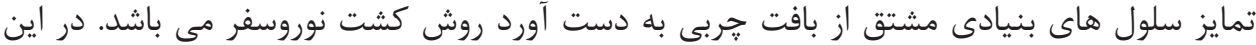

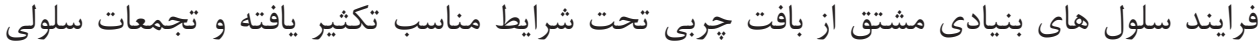

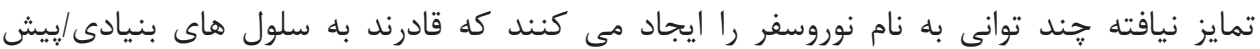

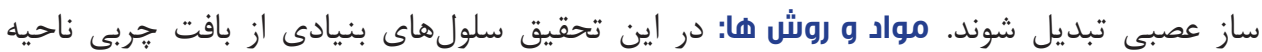

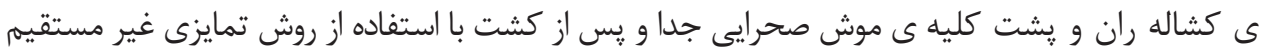

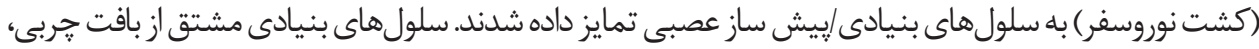

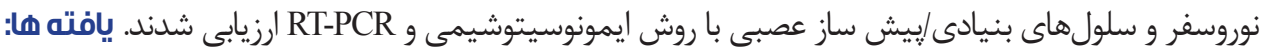

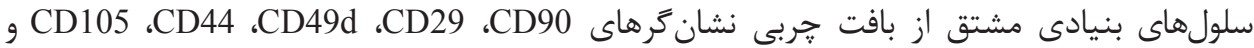

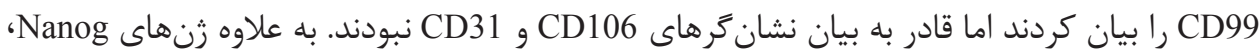

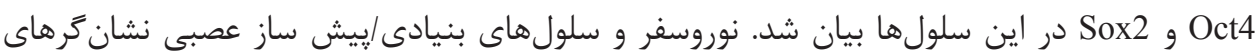

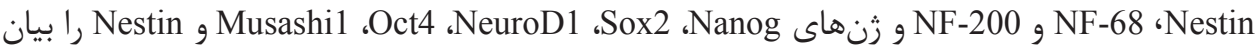

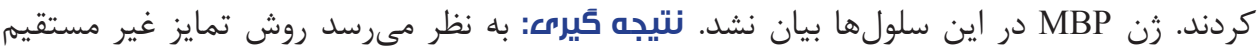

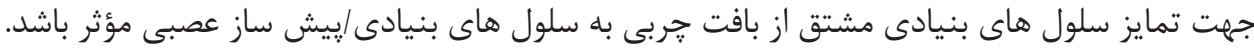

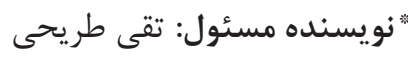

آدرس الكترونيكى: takialtr@modares.ac.ir 


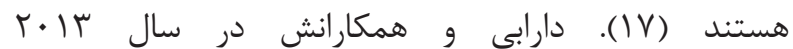

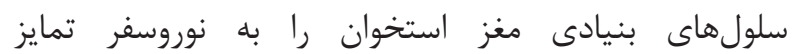

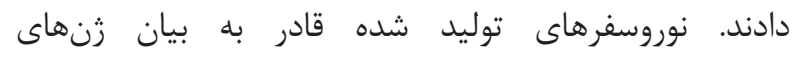

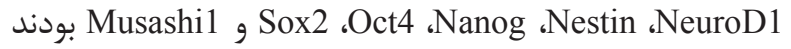
(1) (1). در اين تحقيق تلاش شده تا سلولهاى بنيادى مشتق از

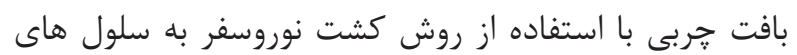
بنيادى/ييش ساز عصبى تمايز داده شوند.

\section{مواد و روش ها - - مان}

جداسازى و كشت سلول هاى بنيادى مشتق از بافت جربى در اين مطالعه با رعايت اصول و مقررات كار با حيوانات (مورد تأييد دانشعاه تربيت مدرس) براى ترائ تهيه

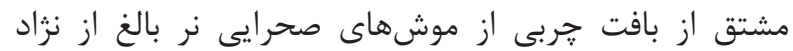
Sprague-Dawley

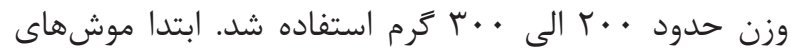
صحرايى به صورت تصادفى انتخاب و بله وسيله لى كلى كلروفرم

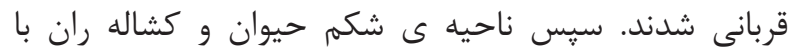

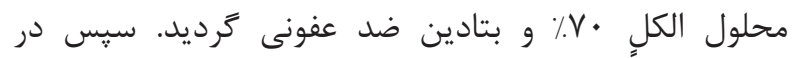

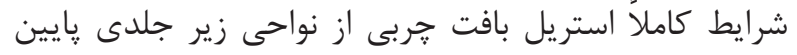

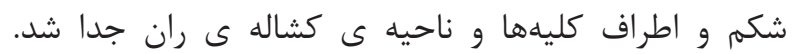

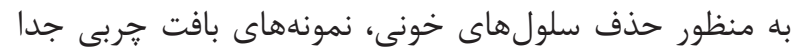

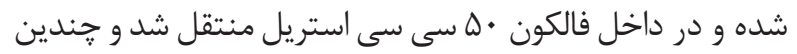

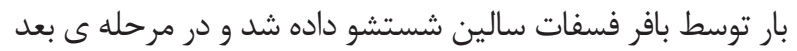

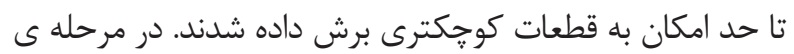

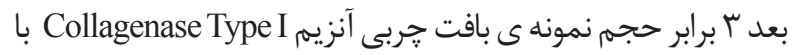

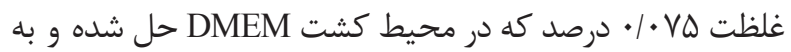

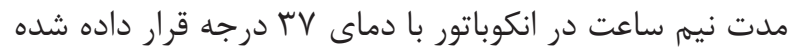

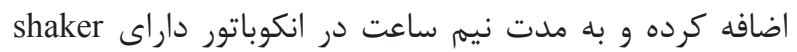

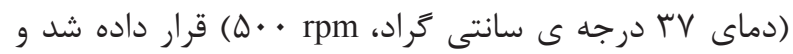

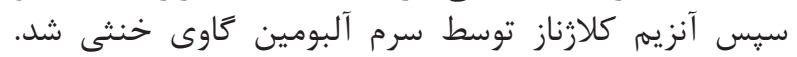

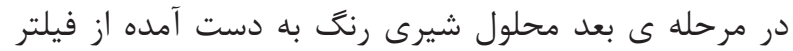

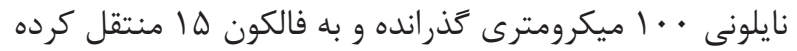

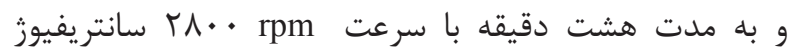

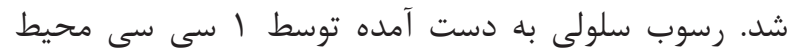
DMEM

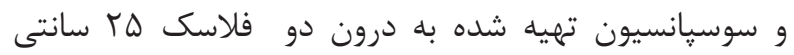

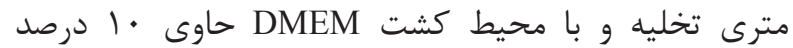

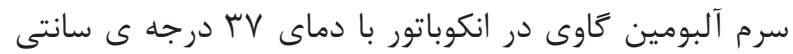

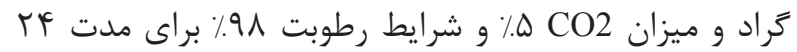

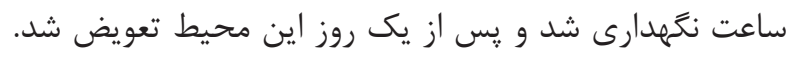

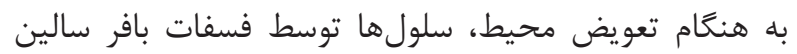

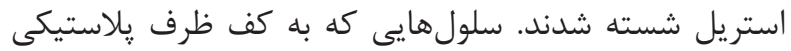

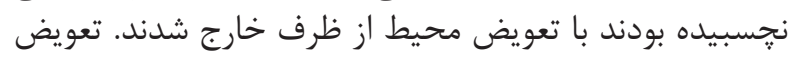

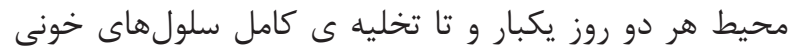

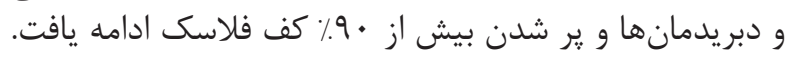

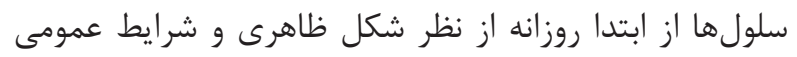

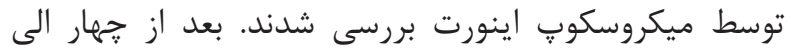

سلول هاى بنيادى قادر به خود تكثيرى (Self-renewal)

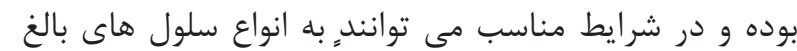

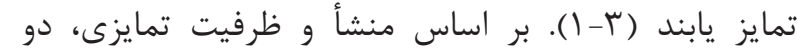

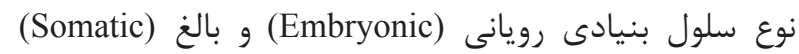

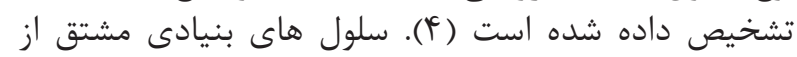

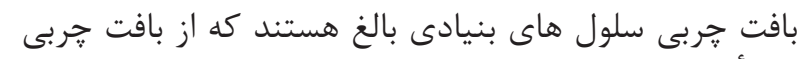

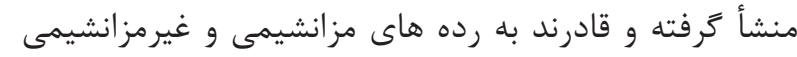

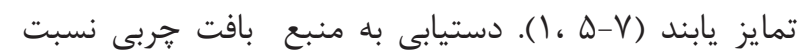

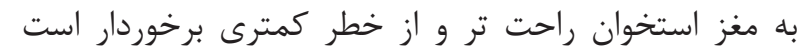

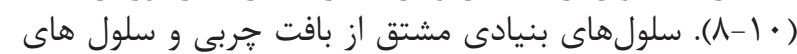

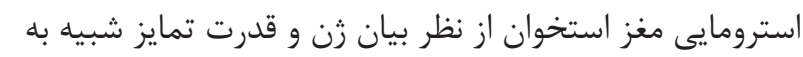

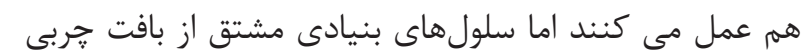

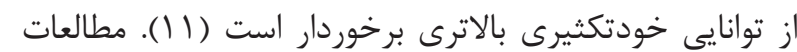

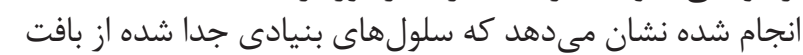

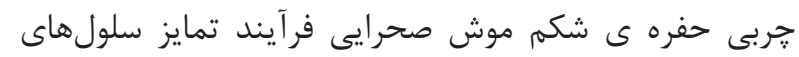

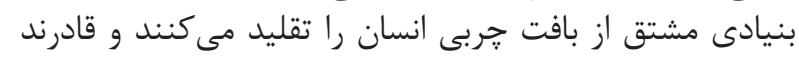

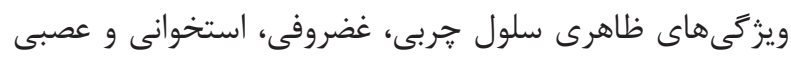

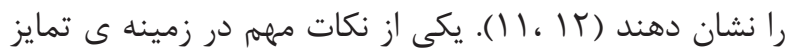

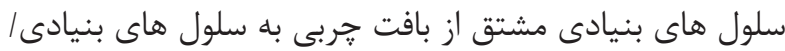

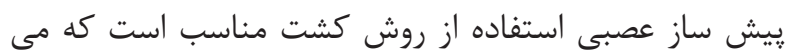
توان به روش كشت نوروسفر اشاره كرد.

روش ايجاد نوروسفر نخستين بار در سال 199 199 توسط رينولدز

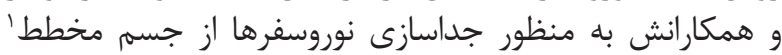

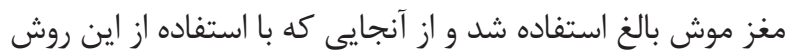

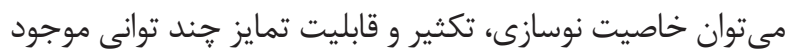

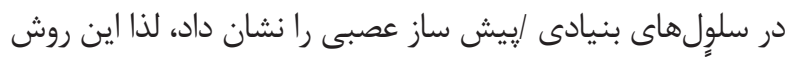

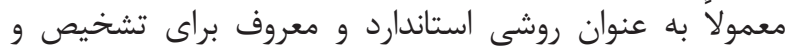

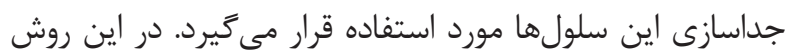

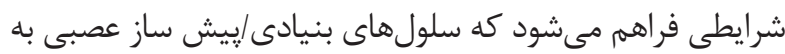

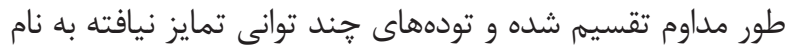

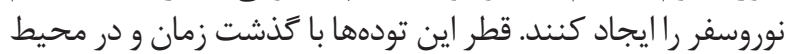

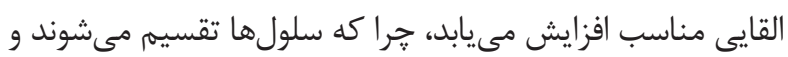

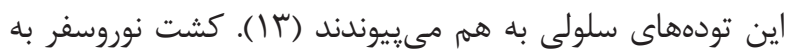

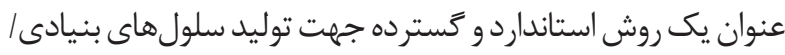

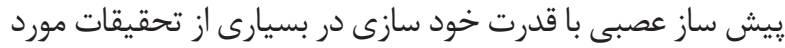

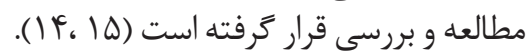

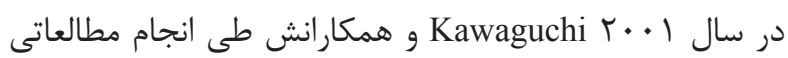

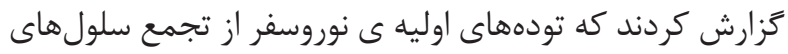

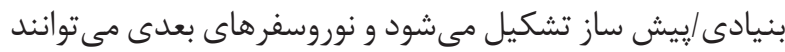

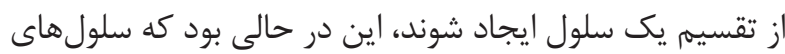
بنيادى/ييش ساز عصبى از نوع سلولهاى

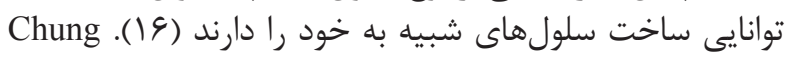

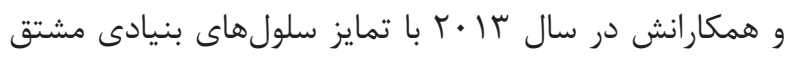

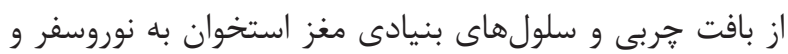

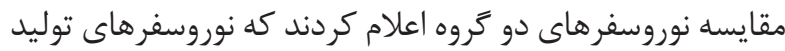

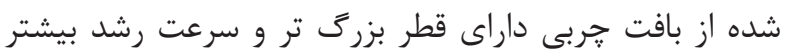

${ }^{1}$ Substantia Nigra 


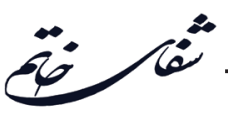

استفاده از تيغ جراحى استريل بريده و در ها ه فيلد مختلف از

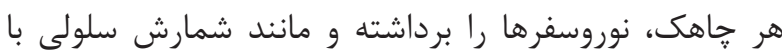

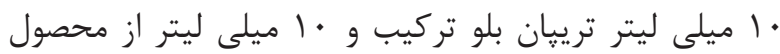

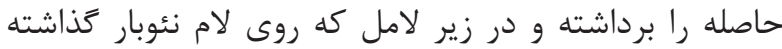

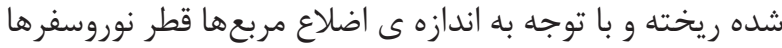

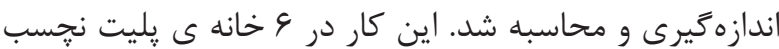

در ه فيلد مختلف ه بار تكرار شد (تصوير ().
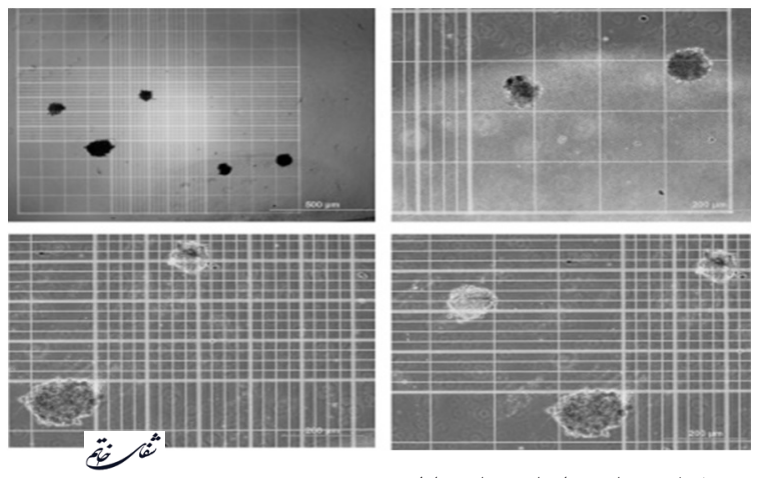

تصوير 1- لام نئوبار همراه با تجمعات سلولى نوروسفر.

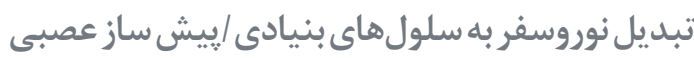

يس از هفت روز نوروسفرهاى شناور به همراه محيط كشت

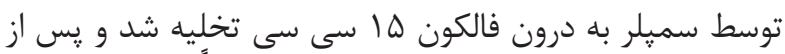

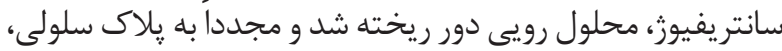

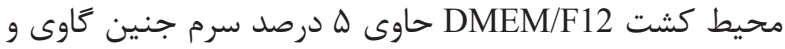

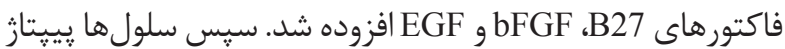

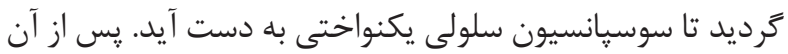

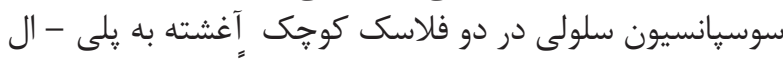

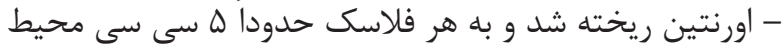

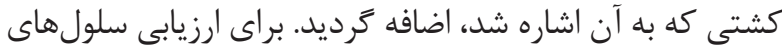

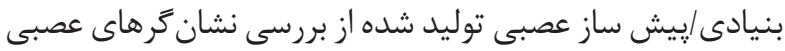

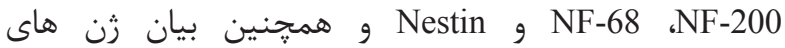
شusashi ،NeuroD1

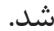

\section{RT-PCR}

سلولهاى بنيادى مشتق از بافت خربى، نوروسفر و سلولهاى

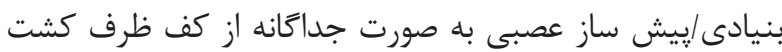

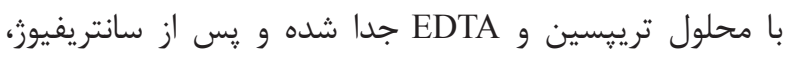

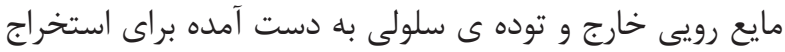

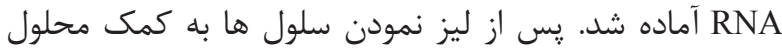
RNX Plus (CinaGen Inc., Tehran, Iran) انجام و RNA حذف شد. سيس واكنش رونويسى cDNA Synthesis Kit(Fermentas) معكوس با استفاده ازفاز

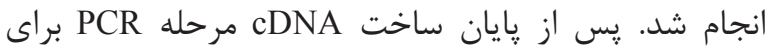

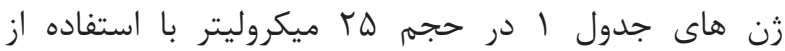

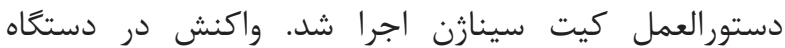
Thermal cycler (Mastercycler Gradient) لازم به توضيح است كه در هر مرحله از انجام PCR به جاى

${ }^{2}$ basic Fibroblast growth factor

${ }^{3}$ Epidermal growth factor
شش روز سلولها ياساز داده شد. بدين منظور محيط كشت

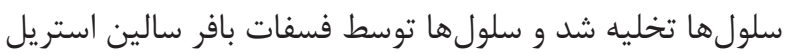

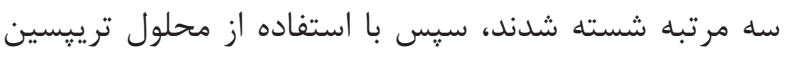

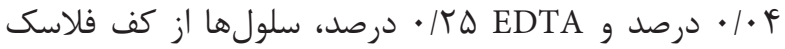

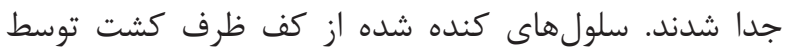

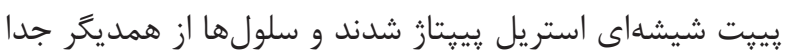

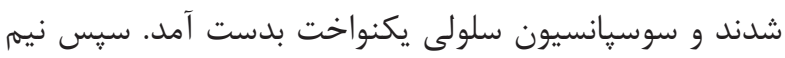

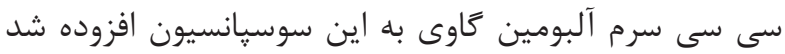

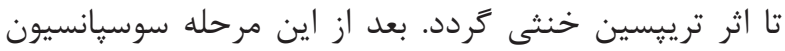

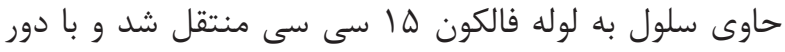

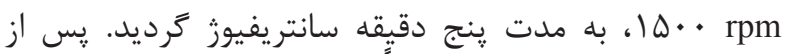

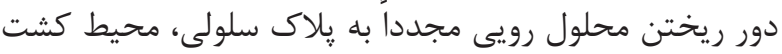

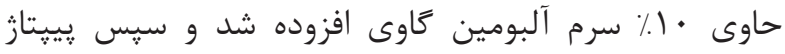

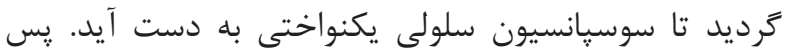

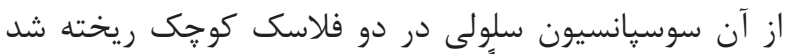

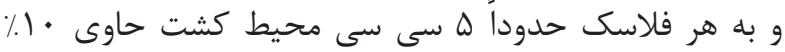

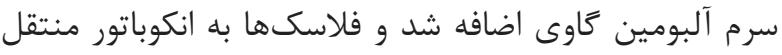

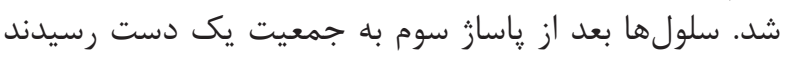

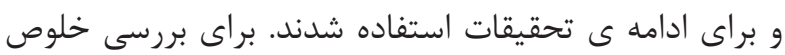

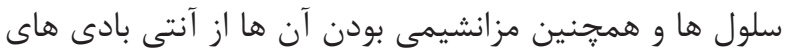

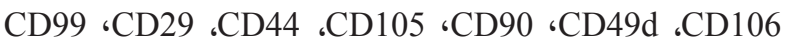

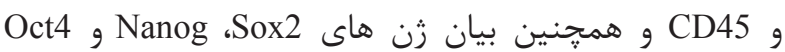

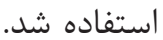

تمايز سلول هاى بنيادى مشتق از بافت جربى به نوروسفر سلولهاى بنيادى مشتق از بافت خربى بعد از ياساز سوم إز

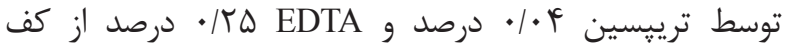

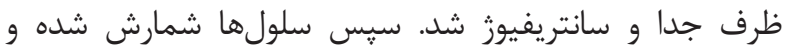

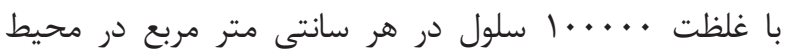

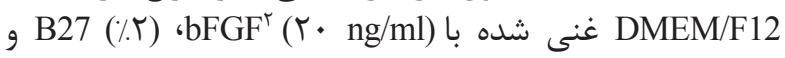
EGF (Y. ng/ml)

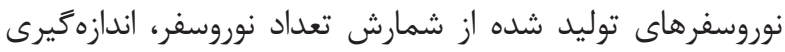

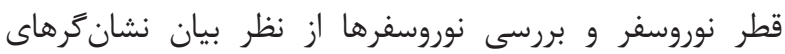

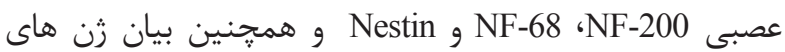
1MBP و Sox2، Oct4،Nanog ،Musashi ،NeuroD1

$$
\text { شمارش تعدادنوروسفرها }
$$

در روزهاى سوم، ششم و دهم تعداد نوروسفرها در ها ناحيه

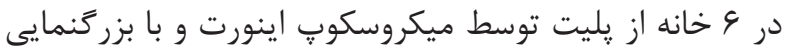
• † × بررسى و يادداشت شد. اين كار ه لبار تكرار شد.

اندازه ئيرى قطر نوروسفر هابا استفاده از لام نئوبار

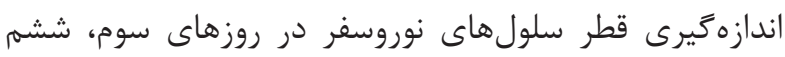

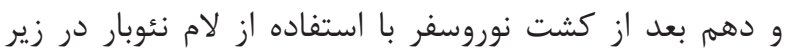

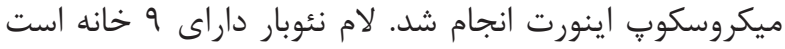

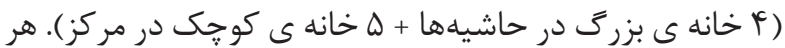

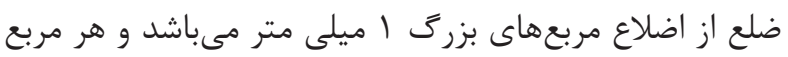

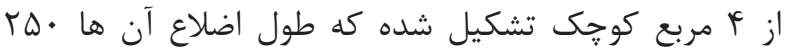

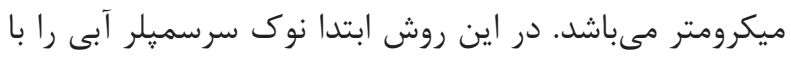


جدول ا- اطلاعات مربوط به برايمرهاى Reverse (Antisense) و زنهاى استفاده شده در مرحله عى القاء به همراه برخى از ويرَّى هاى آنها.

\begin{tabular}{|l|l|l|l|l|}
\hline Musashi1 & NM-148890 & CACTGCTTATGGTCCGATGG & GGTGAAGGCTGTCGCAATC & 274 \\
\hline NeuroD1 & NM-019218 & CTACTTGTTACCTTTCCCATGC & GCTAAGGCAACGCAATAAC & 216 \\
\hline MBP & NM-001025294 & TTCCAAAGAGACCCACACTG & AAGGTCGGTCGTTCAGTCAC & 247 \\
\hline Nestin & NM-012987 & AAGGCTCAGGAGTTCCAGG & TACGGCTTTATTCAGGGAG & 244 \\
\hline Sox2 & NM-001109181 & CCGTTACAGACAAGGAAGG & CAACGATATCAACCTGCATG & 194 \\
\hline Nanog & NM-001100781 & TTCAAGACCAGCCTGTACT & GCACTGGTTTATCATGGTAC & 219 \\
\hline Oct4 & NM-001009178 & GGCTGTGTCCTTTCCTCT & TCTCTTTGTCTACCTCCCTTC & 218 \\
\hline GAPDH & NM-017008.4 & GGAGTAAGAAACCCTGGACCAC & GAGGGTGCAGCGAACTTTATTG & 205 \\
\hline
\end{tabular}

يافته ها

جداسازى و كشت سلول هاى بنيادى مشتق از بافت جربى

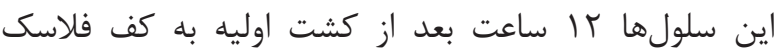

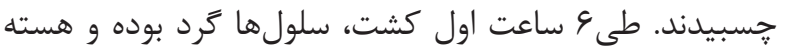

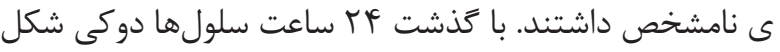

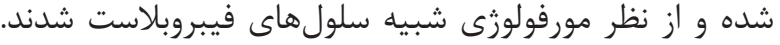

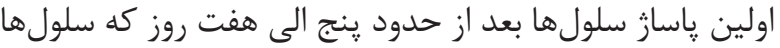

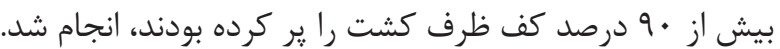

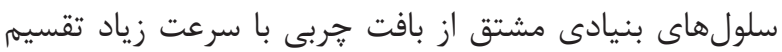

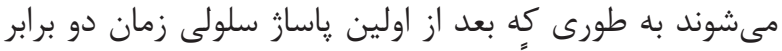

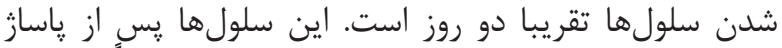

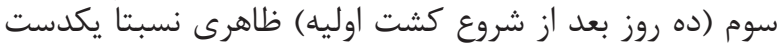

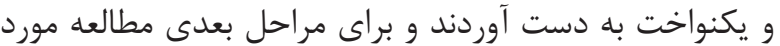

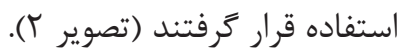

يك كنترل منفى نيز به كار خرفته شد. ميكروتيوٍ

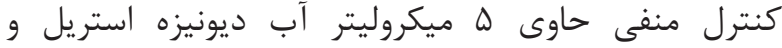

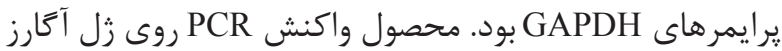

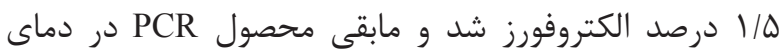

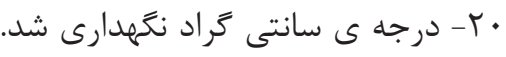

$$
\text { تجزيه و تحليل آمارى }
$$

اطلاعات به دست آمده شامل درصد بيان ماركرهاى سطحى دري

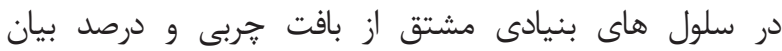

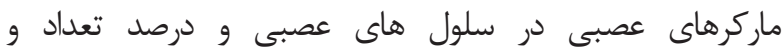
قطر نوروسفر، توسط آزمون آمارى آناليز واريانس يك دائ طرفه SPSS version16 و و به وآزمون TUKEY (ANOVA)

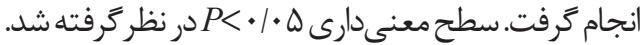
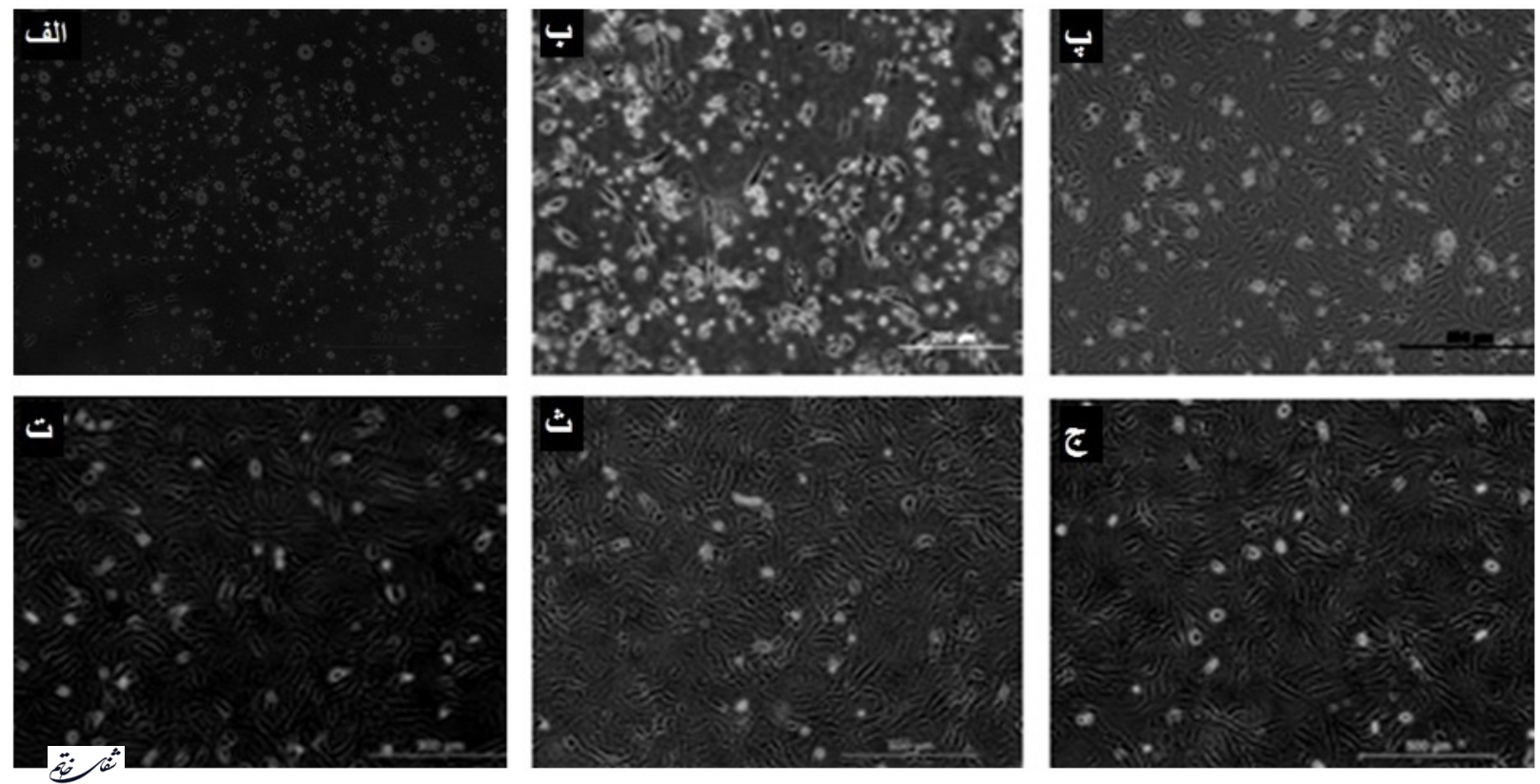

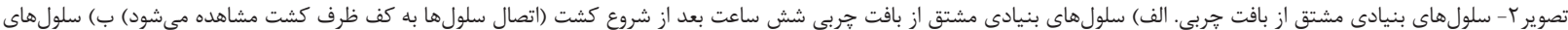

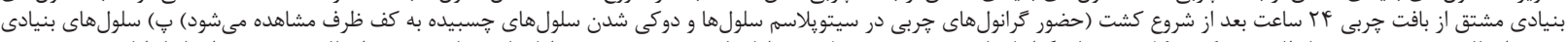

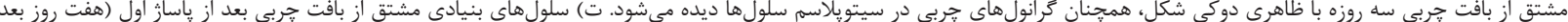

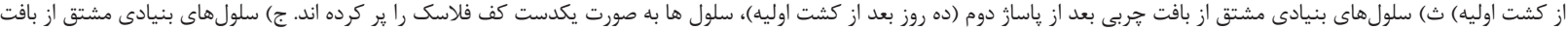


Propidiume Iodide

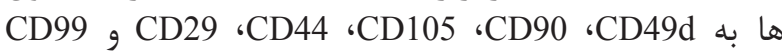

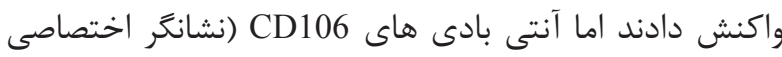

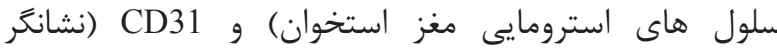
اختصاصى سلول هاى اندوتليالى) بيان نشدند.
براى اثبات استرومايى بودن سلول ها و تعيين خلوصشان

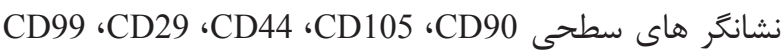

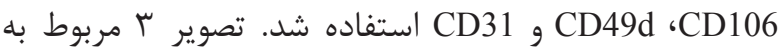

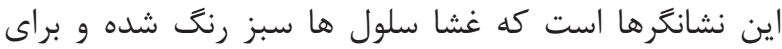
تعيين درصد سلول هاى مثبت، هسته
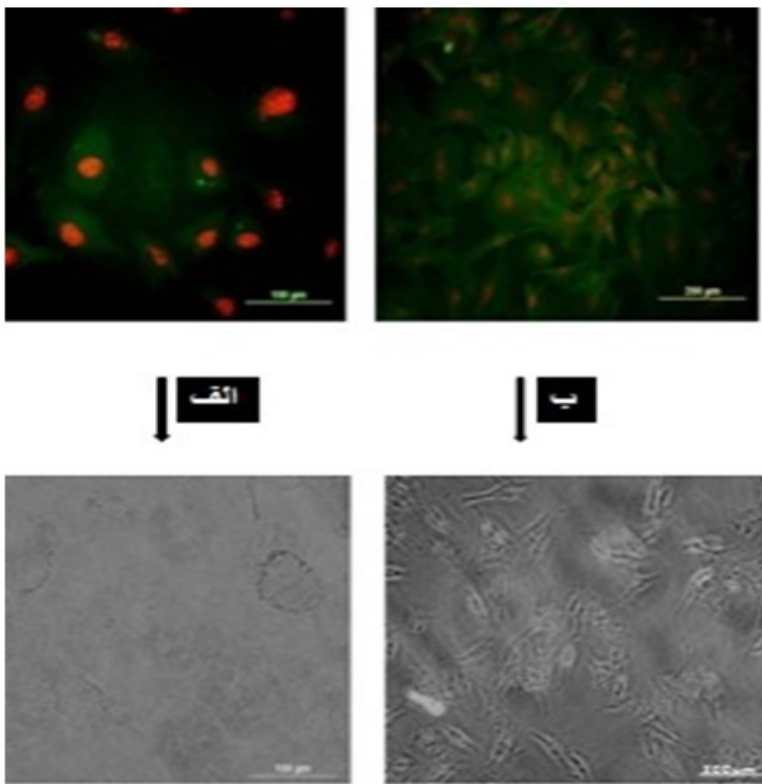

CD49d

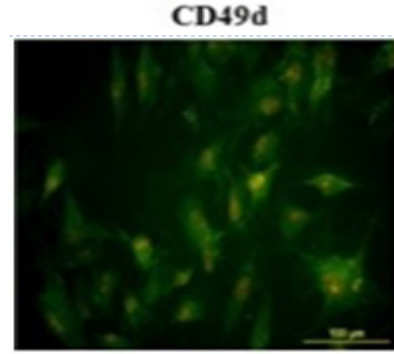

|ت
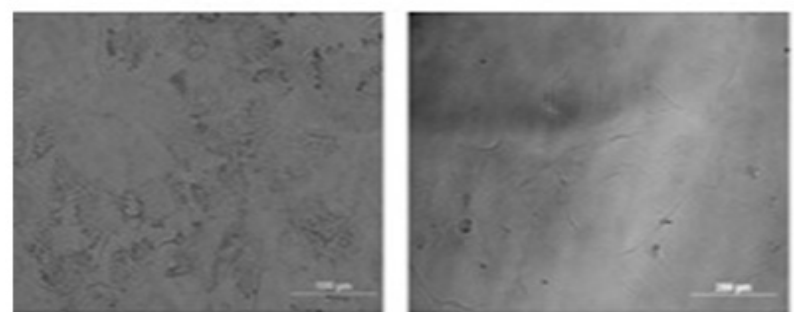

CD99
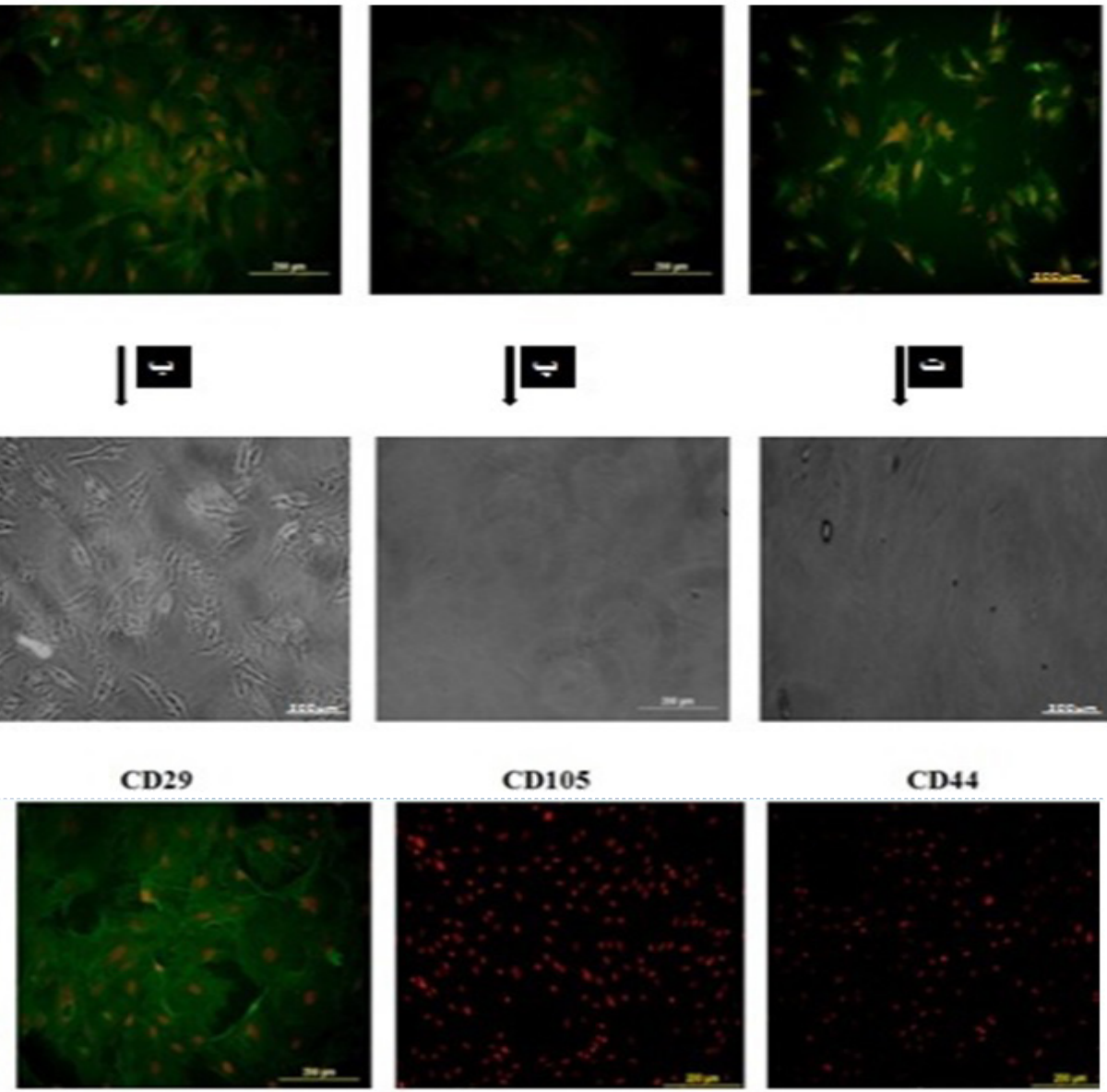

E

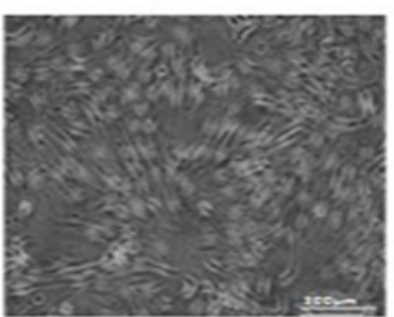

CD31
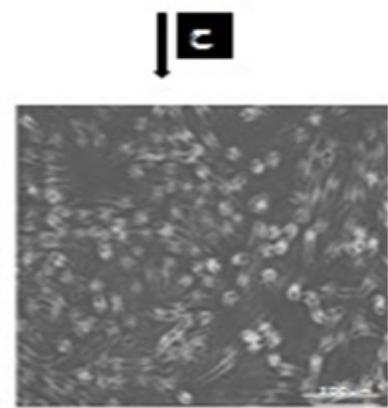

CD106

\section{CD90}

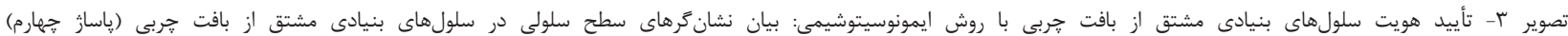

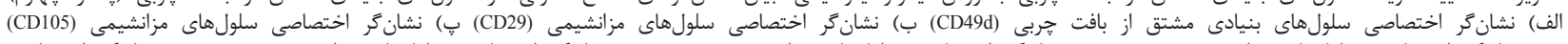

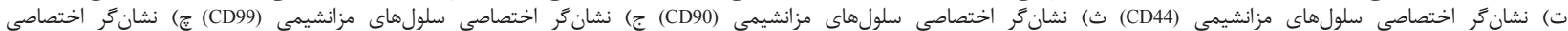

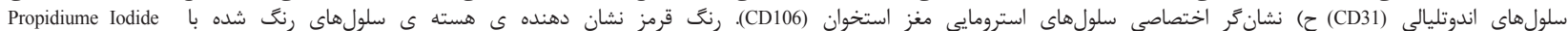

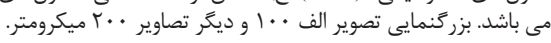


نمودار ا مقايسه ى تعداد نوروسفرها را نشان مى مدهد. تعداد

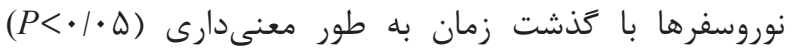

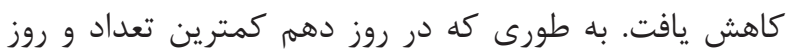

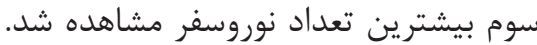
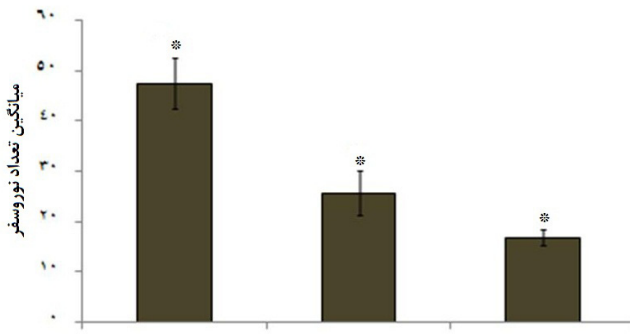

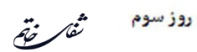

روزششهم

روز دهمر

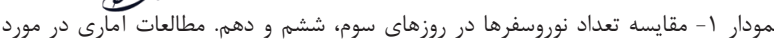

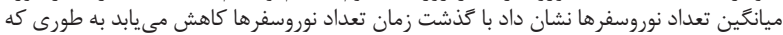

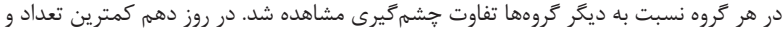

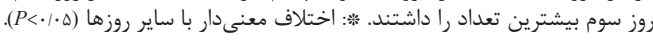

نمودار r مقايسه ى قطر نوروسفرها را نشان مى مدهد قطر

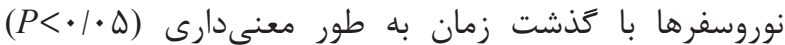

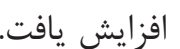

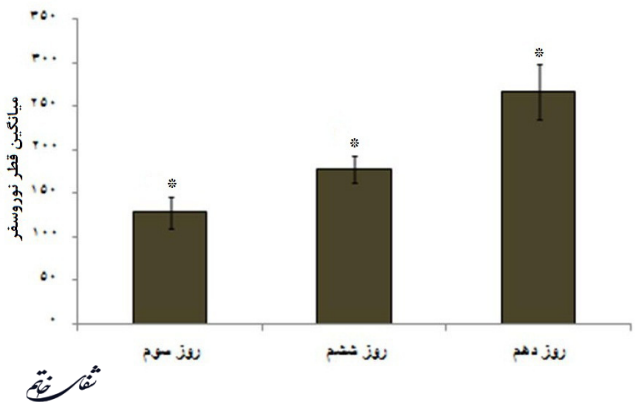

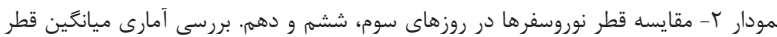

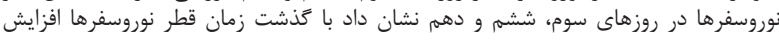

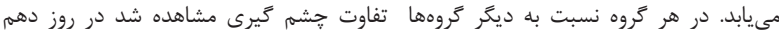

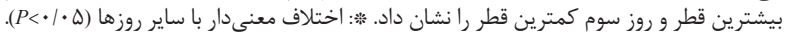

بررسى ايمونوسيتوشيمى نوروسفرها در روز روز هفتم نشان

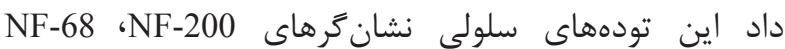

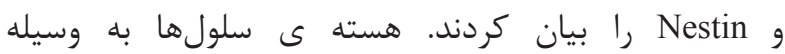
رنغ آميزى شد (تصوير \&). Propidiume Iodide
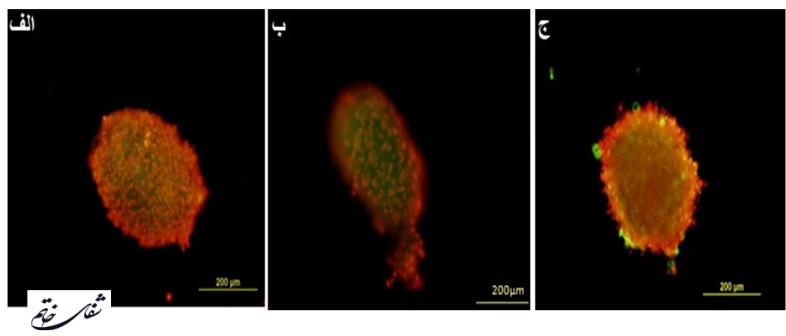

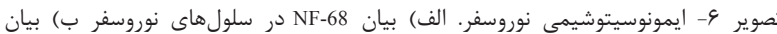

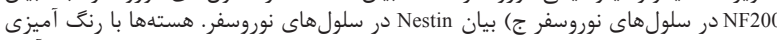

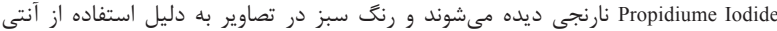

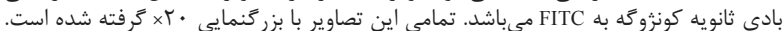

در بررسى RT-PCR تجمعات نوروسفر، mRNA زن هاى

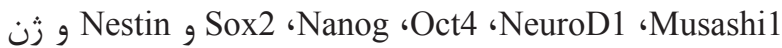

همجنين در بررسى RT-PCR اين سلول ها، mRNA رن هاى Sanog ، Sox2 زن GAPDH به عنوان كنترل داخلى استفاده گرديد (تصوير أ).

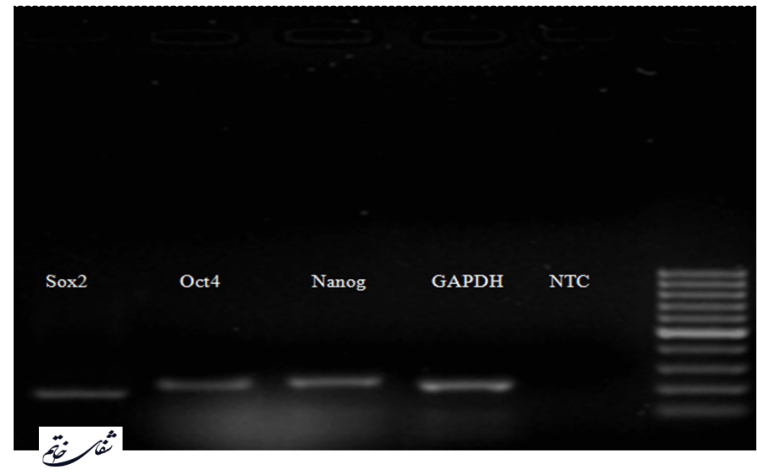

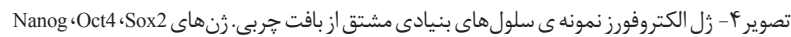

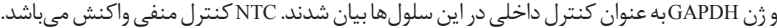

$$
\text { توليد نوروسفر }
$$

سلولهاى بنيادى مشتق از بافت جربى، يكى ساعت بعد از

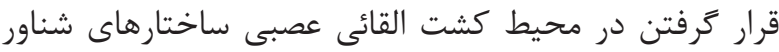
و كروى شكل با سلول هاى گرد و ور هسته

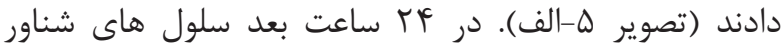

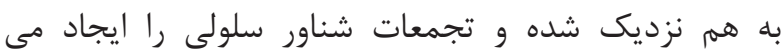

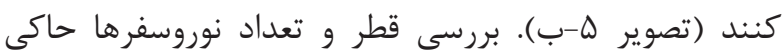

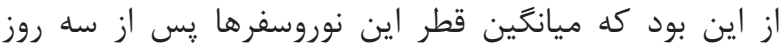

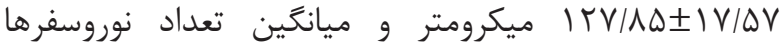

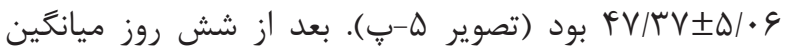

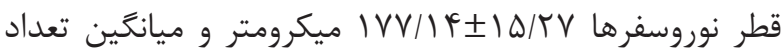
نوروسفرها

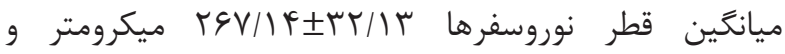

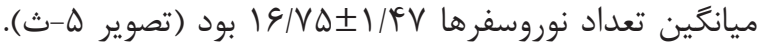

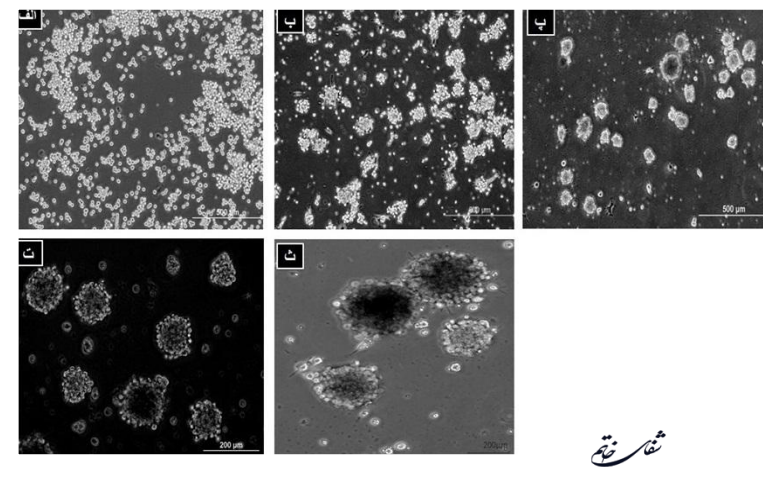

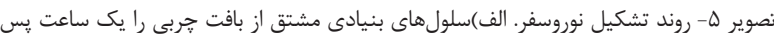

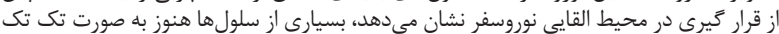

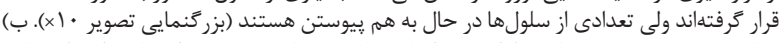

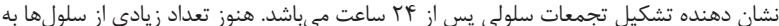

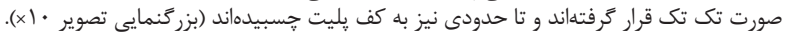

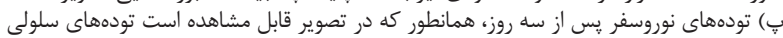

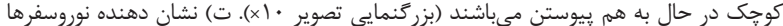

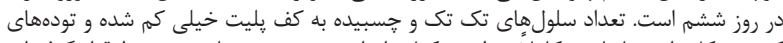

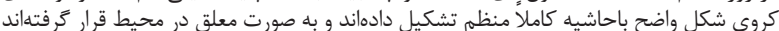

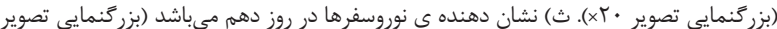


بودند و به كف ظرف كشت اتصال داشتند (تصوير ^-الف).

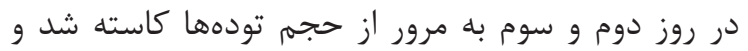

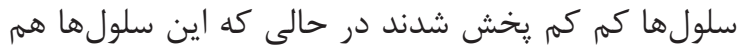

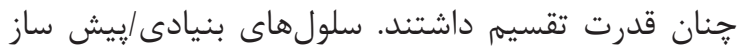

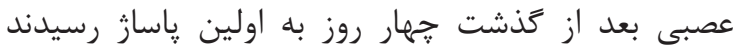

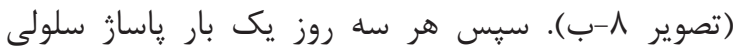

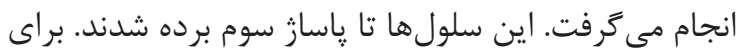
تعيين سرنوشت سلول ها، نشانگر هاى Nestin

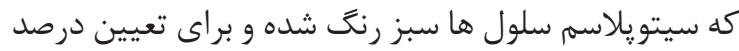

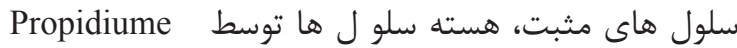

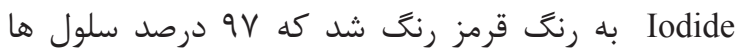

GAPDH به عنوان كنترل داخلى به خوبى بيان شد درحالى دانى دان دان كه باند مشخصى در بيان mRNA زن

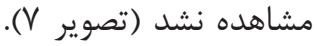

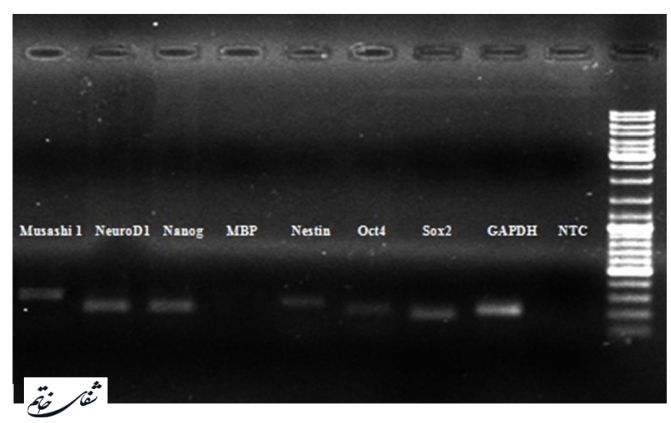

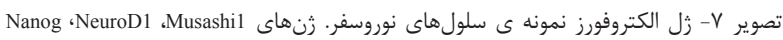

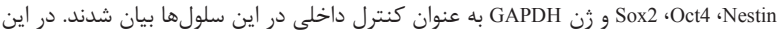

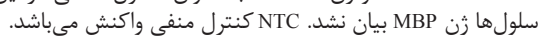
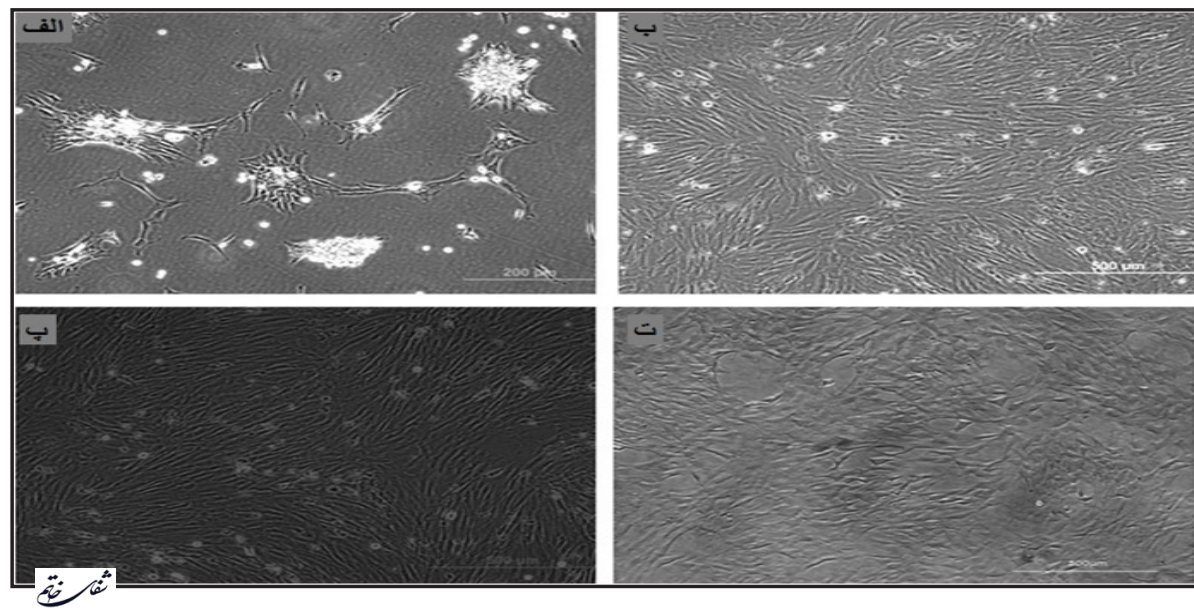

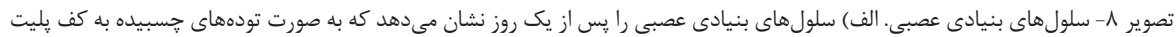

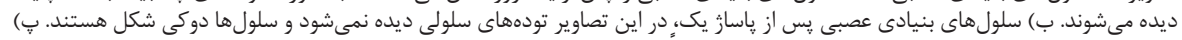

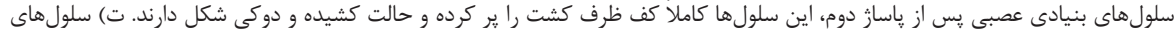

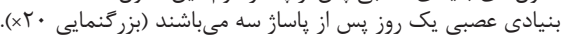

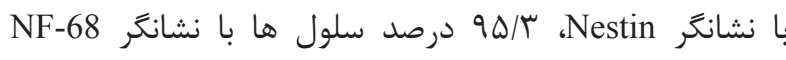

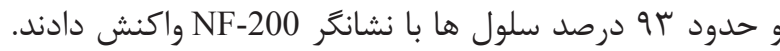

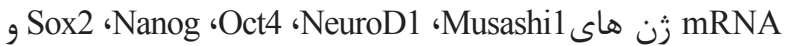
Nestin

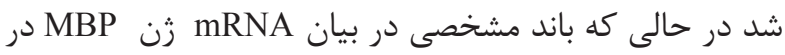
زل الكتروفورز مشاهده نشد (تصوير • ()).

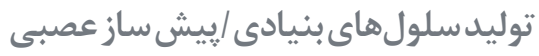

نوروسفرهاى تشكيل شده در مرحلهى قبلى آزمايش در محيط

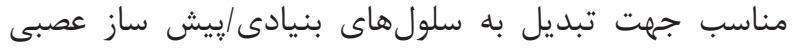

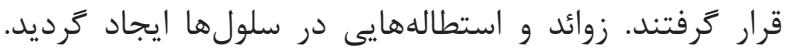

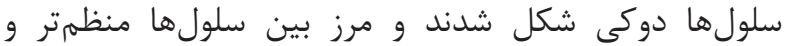
مشخصتر بود. در روز اول ابتدا اين سلولهن بـ بن به صورت توده

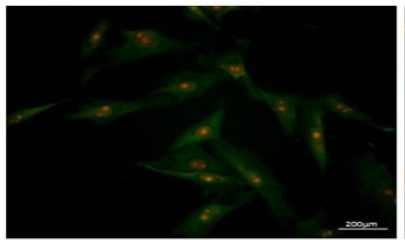

|
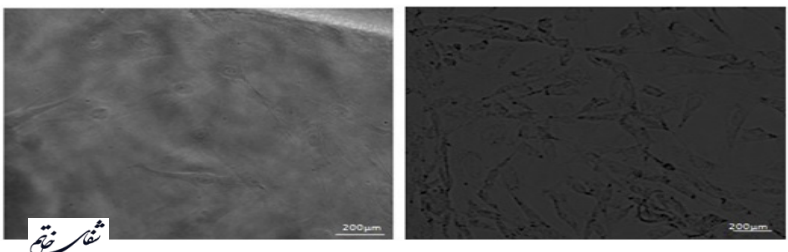

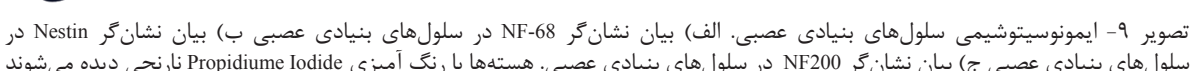

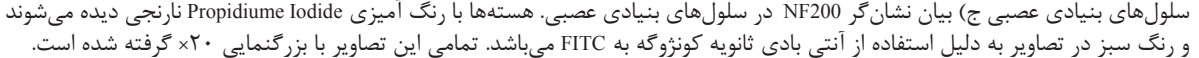

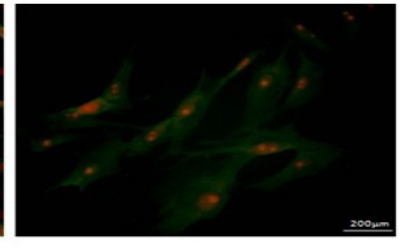

IE

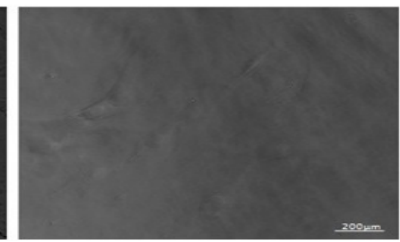


سلولهاى بنيادى مزانشيمى بافت جربى به ظراف كمتر از rاساعت انجام مى كيرد (TV)

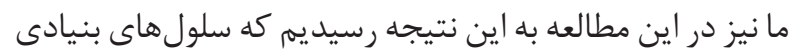

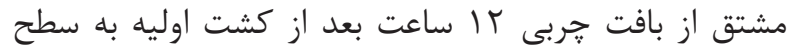

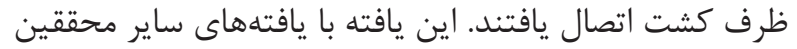

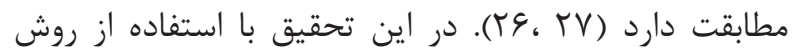

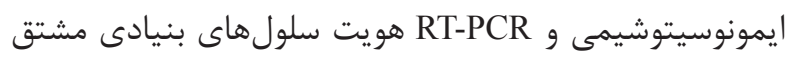

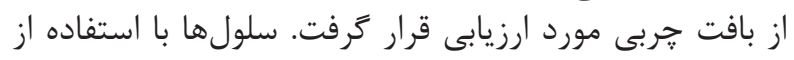

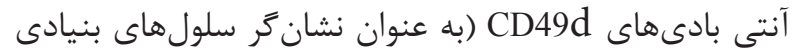

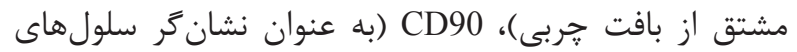

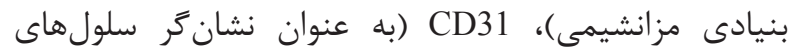

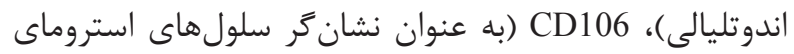

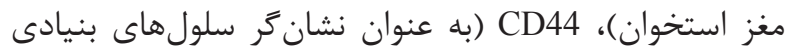

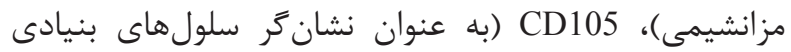

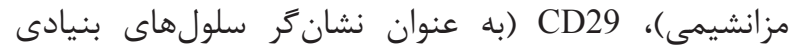

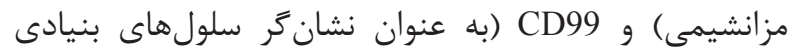

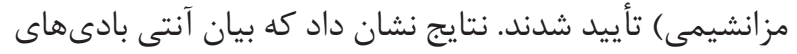

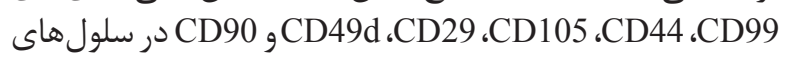

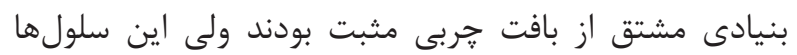

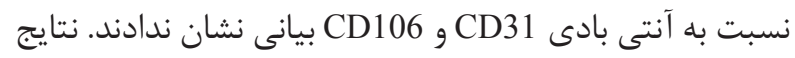

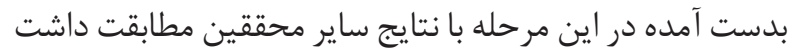

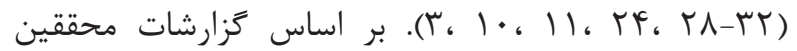

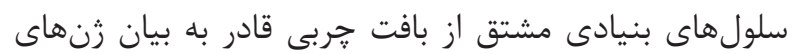

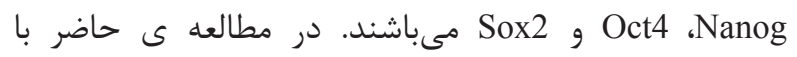

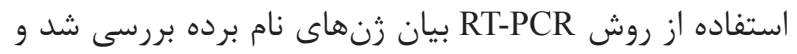

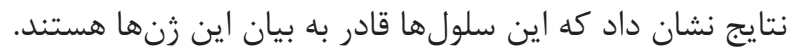

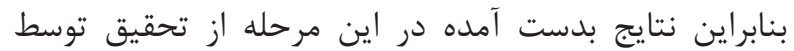

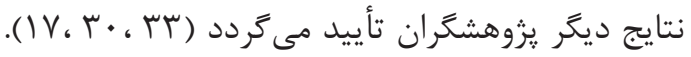

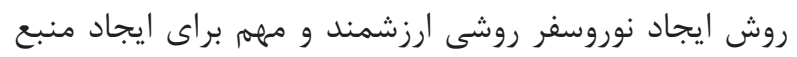

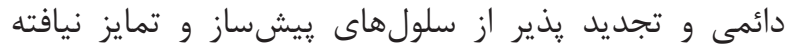

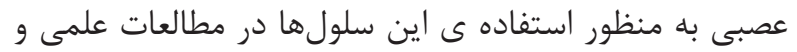

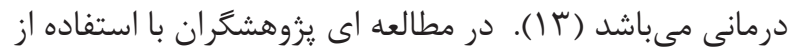

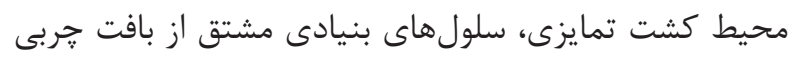

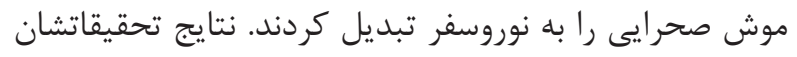

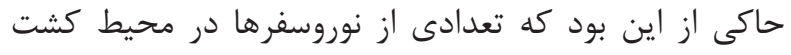

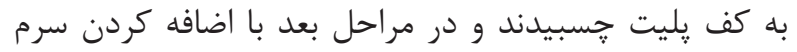

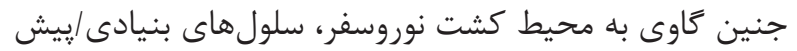

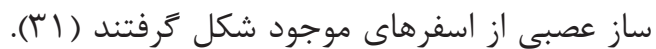

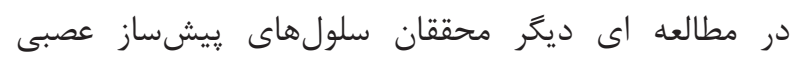

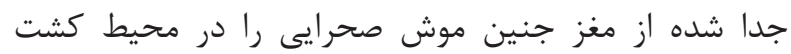

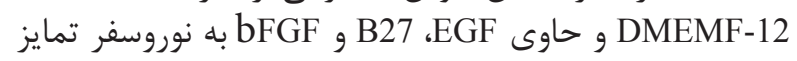
دادند و سيس با افزودن سرم جنين كاوى باوى به محيط كشت،

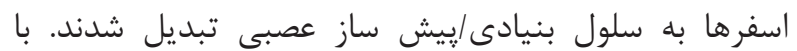

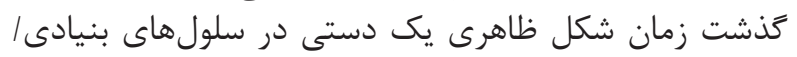

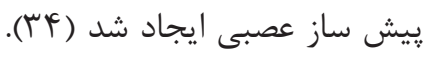

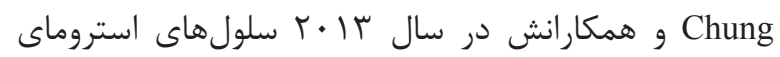

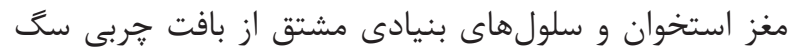

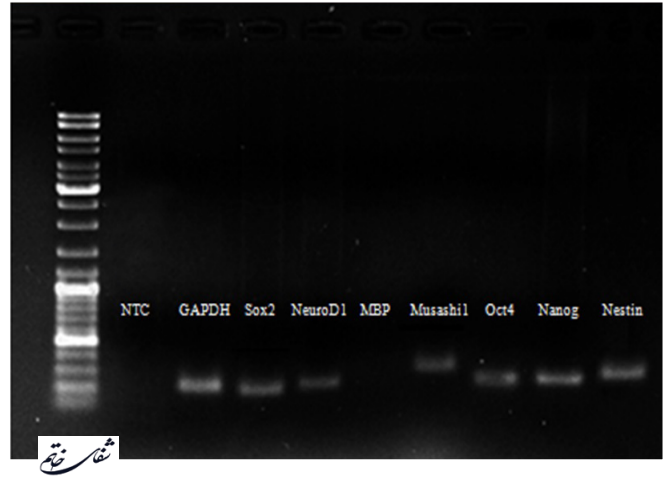

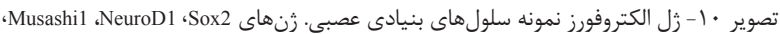

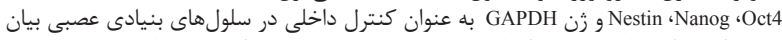

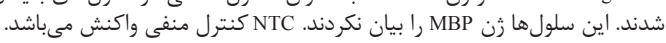

بحث و نتيجه كيرى

استراتزى سلول درمانى در بيمارىهاى مخرب سيسته

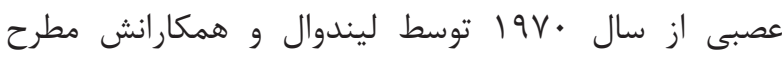

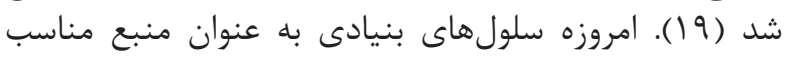

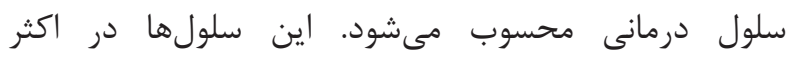

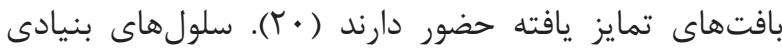

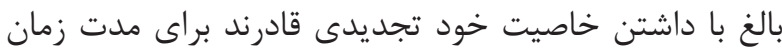

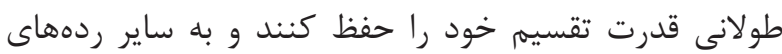

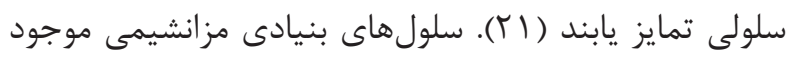

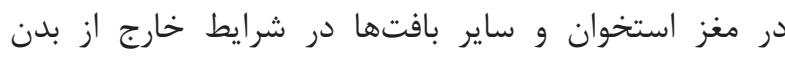
(In vitro)

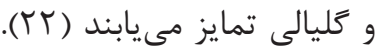

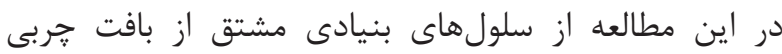

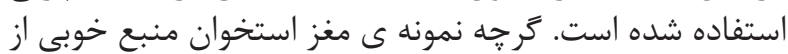

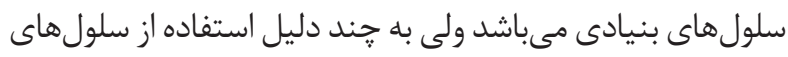

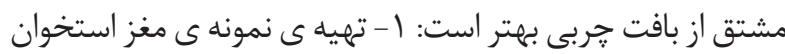

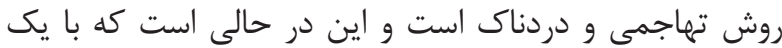

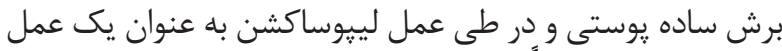

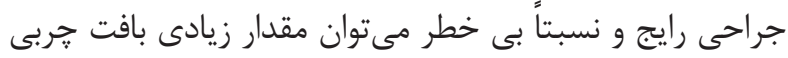

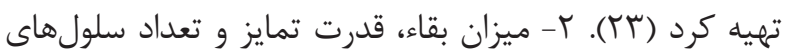

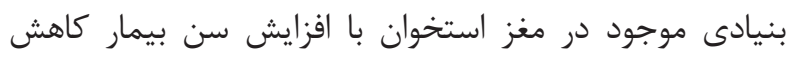

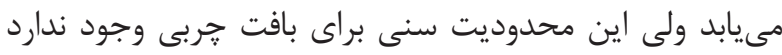

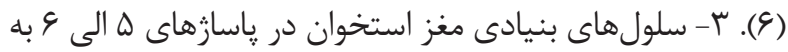

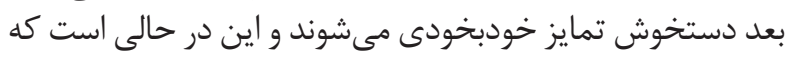

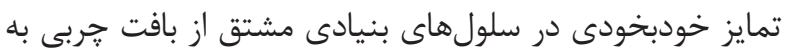

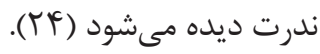

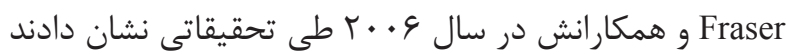

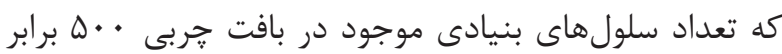

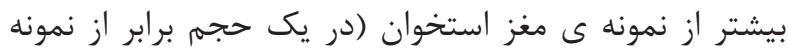

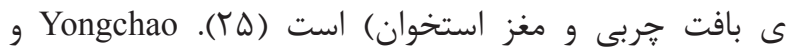

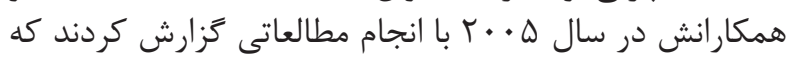

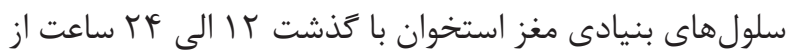

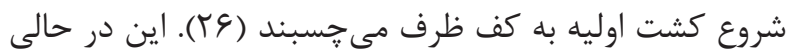

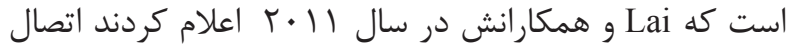


سلولهاى بنيادى /ييش ساز عصبى از نظر بيان آنتى بادىهاى Nestin

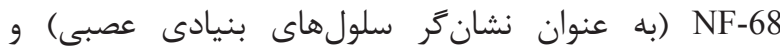

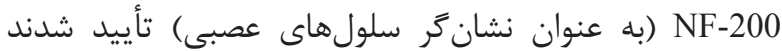

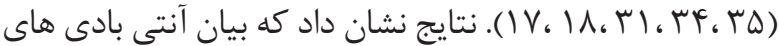

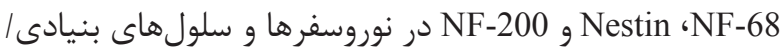

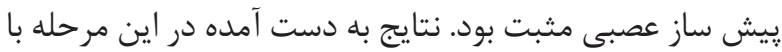

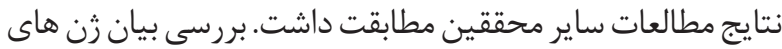
و Musashi1 NeuroD1 OCt4 ،MBP ،Nestin ،Nanog Sox2 با روش RT-PCR نشان داد كه در دري تجمعات نوروسفر و سلولهاى بنيادى/ييش ساز عصبى زن هان

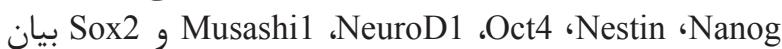

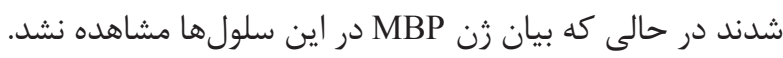

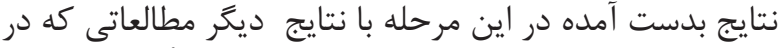

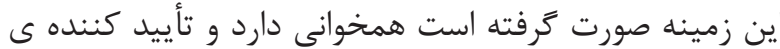

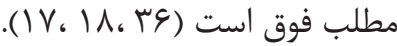

نتايج به دست آمده در اين تحقيق كوياى اين است كه با استفاده

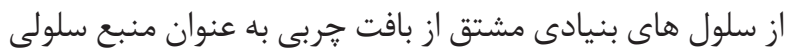

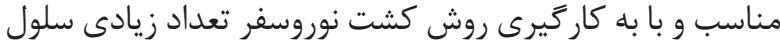

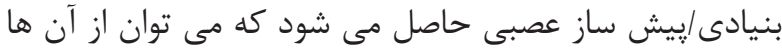
براى تحقيقات آتى استفاده كرد.

$$
\text { تقدير و تشكر }
$$

از معاونت محترم يزوهشى دانشاهاه تربيت مدرس و مركز تحقيقات إنيقات

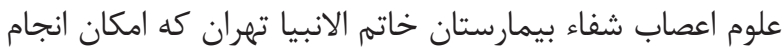

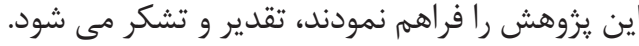

1. Aschettino J, Dalton-Petille S, Keaffer L, zerszunowic J, Adams D. Stem Cells and Society. B.S.c.thesis. Worcester Polytechnic Institute. 2012.

2. McGraw J, Hiebert G, Steeves J. Modulating astrogliosis after neurotrauma. J Neurosci Res. 2001; 63(2): 109-15.

3. Tapp H, Hanley EN, Patt JC, Gruber HE. Adipose-derived stem cells: characterization and current application in orthopaedic tissue repair. Exp Bio Med. 2009; 234(1): 1-9.

4. Zhao LR, Duan WM, Reyes M, Keene CD, Verfaillie CM, Low WC. Human bone marrow stem cells exhibit neural phenotypes and ameliorate neurological deficits after grafting into the ischemic brain of rats. Exp Neurol. 2002; 174(1): 11-20.
را در محيط كشت تمايزى به نوروسفر تمايز دادند. اسفرهاى

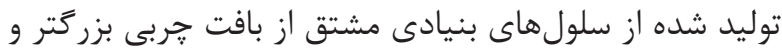

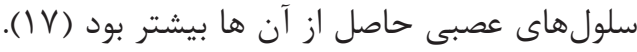

Darabi

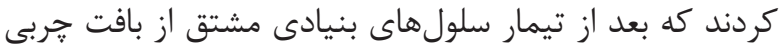

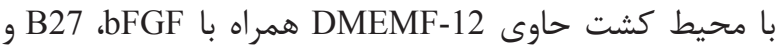

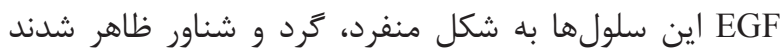

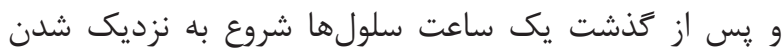

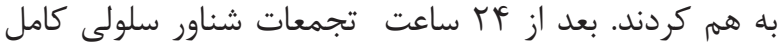

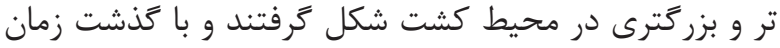

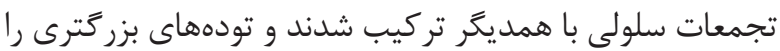

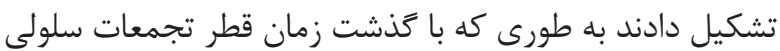

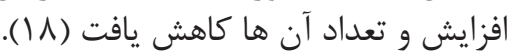

نتايج حاصل از مطالعه ى ما در اين مرحله، تأييدى بر نتايج

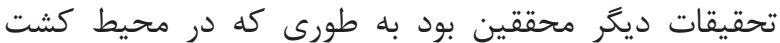

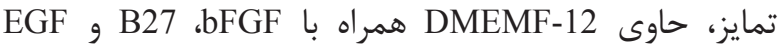

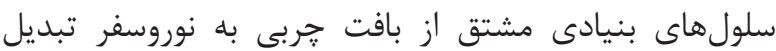

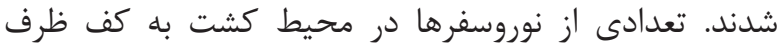

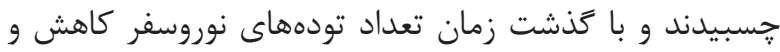

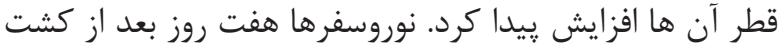

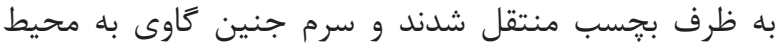

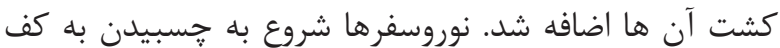

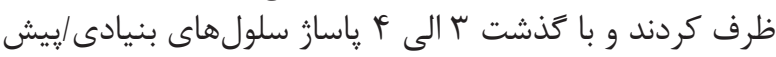

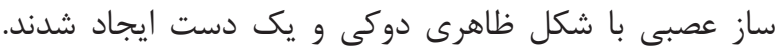

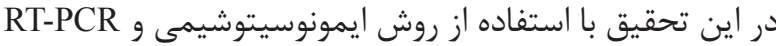

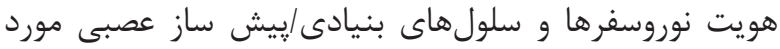

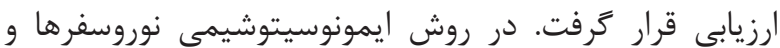

منابع

5. Hsieh J, Nakashima K, Kuwabara T, Mejia E, Gage FH. Histone deacetylase inhibition-mediated neuronal differentiation of multipotent adult neural progenitor cells. Proc Natl Acad Sci U S A. 2004; 101(47): 16659-64.

6. Huang $\mathrm{T}$, He D, Kleiner G, Kuluz J. Neuron-like differentiation of adipose-derived stem cells from infant piglets in vitro. J Spinal Cord Med. 2007; 30: 35-40.

7. Lotfi AS, Khoshdel A, Soleimani M, Daliri M, Razban V, Adibi B. High yield generation of hepatocyte like cells from adipose derived stem cells. SRE. 2012; 7(10): 1141-7.

8. Golipoor Z, Kashani-Ragerdi I, Mohammad A, Hassanzadeh GH, Malek F, Mahmoudi R. Differentiation of adipose-derived 
stem cells into schwann cell phenotype in comparison with bone marrow stem cells. Iran J Basic Med Sci. 2010; 13 (3): 76-84.

9. Herzog EL, Chai L, Krause DS. Plasticity of marrowderived stem cells. Blood. 2003; 102(10): 3483-93.

10. Jang S, Cho HH, Cho YB, Park JS, Jeong HS. Functional neural differentiation of human adipose tissue-derived stem cells using bFGF and forskolin. BMC Cell Biol. 2010; 11(1): 25.

11. Kingham PJ, Kalbermatten DF, Mahay D, Armstrong SJ, Wiberg M, Terenghi G. Adipose-derived stem cells differentiate into a Schwann cell phenotype and promote neurite outgrowth in vitro. Exp Neurol. 2007; 207(2): 267-74.

12. Wu YP, Chen WS, Teng C, Zhang N. Stem cells for the treatment of neurodegenerative diseases. Molecules. 2010; 15(10): 6743-58.

13. Yang Q, Mu J, Li Q, Li A, Zeng Z, Yang J, et al. A simple and efficient method for deriving neurospheres from bone marrow stromal cells. Biochem Bioph Res Commun. 2008; 372(4): 520-4.

14. Engstrom CM, Demers D, Dooner M, McAuliffe C, Benoit BO, Stencel K, et al. A method for clonal analysis of epidermal growth factor-responsive neural progenitors. J Neurosci Methods. 2002; 117(2): 111-21.

15. Nakamura Y, Sakakibara S-i, Miyata T, Ogawa M, Shimazaki T, Weiss S, et al. The bHLH gene hes1 as a repressor of the neuronal commitment of CNS stem cells. The J Neurosci. 2000; 20(1): 283-93.

16. Kawaguchi A, Miyata T, Sawamoto K, Takashita N, Murayama A, Akamatsu W, et al. Nestin-EGFP transgenic mice: visualization of the self-renewal and multipotency of CNS stem cells. Mol Cell Neurosci. 2001; 17(2): 259-73.

17. Chung C, Fujita N, Kawahara N, Yui S, Nam E, Nishimura R. A Comparison of Neurosphere Differentiation Potential of Canine Bone Marrow-Derived Mesenchymal Stem Cells and Adipose-Derived Mesenchymal Stem Cells. J Vet Med Sci. 2013; 75(7): 879-86.

18. Darabi S, Tiraihi T, Ruintan A, Abbaszadeh HA, Delshad A, Taheri T. Polarized neural stem cells derived from adult bone marrow stromal cells develop a rosette-like structure. In Vitro Cell Dev Biol Anim. 2013; 49(8): 638-52.
19. Lindvall O, Björklund A. Cell replacement therapy: helping the brain to repair itself. NeuroRx. 2004; 1(4): 379-81.

20. Dazzi F, Ramasamy R, Glennie S, Jones SP, Roberts I. The role of mesenchymal stem cells in haemopoiesis. Blood Rev. 2006; 20(3): 161-71.

21. Sylvester KG, Longaker MT. Stem cells: review and update. Arch Surg. 2004; 139(1): 93-9.

22. Jiang Y, Jahagirdar BN, Reinhardt RL, Schwartz RE, Keene CD, Ortiz-Gonzalez XR, et al. Pluripotency of mesenchymal stem cells derived from adult marrow. Nature. 2002; 418(6893): 41-9.

23. Cheng KH, Kuo TL, Kuo KK, Hsiao CC. Human adiposederived stem cells: Isolation, characterization and current application in regeneration medicine. GMBHS. 2011; 3(2): 53-62.

24. Wang CY, Yang F, He XP, Je HS, Zhou JZ, Eckermann K, et al. Regulation of neuromuscular synapse development by glial cell line-derived neurotrophic factor and neurturin. J Biol Chem. 2002; 277(12): 10614-25.

25. Fraser JK, Wulur I, Alfonso Z, Hedrick MH. Fat tissue: an underappreciated source of stem cells for biotechnology. Trends Biotechnol. 2006; 24(4): 150-4.

26. Yongchao W, Qixin Z, Xiaodong G, Zhongping X, Yuntao W, Jie H. Differentiation of bone marrow mesenchymal cells to neural cells. J Huazhong Univ Sci Technolog Med Sci. 2005; 25(5): 488-90

27. Lai K, Zeng K, Zeng F, Wei J, Tan G. Allogeneic adiposederived stem cells suppress Th17 lymphocytes in patients with active lupus in vitro. Acta Biochim Biophys Sin. 2011; 43(10): 805-12.

28. Izadpanah R, Joswig T, Tsien F, Dufour J, Kirijan JC, Bunnell BA. Characterization of multipotent mesenchymal stem cells from the bone marrow of rhesus macaques. Stem Cells Dev. 2005; 14(4): 440-51.

29. Xiao Y, Mareddy SR, Crawford RW. Clonal characterization of bone marrow derived stem cells and their application for bone regeneration. Int J Oral Sci. 2010; 2(3): 127-35.

30. Park E, Patel AN. Changes in the expression pattern of 
mesenchymal and pluripotent markers in human adiposederived stem cells. Cell Biol Int. 2010; 34(10): 979-84.

31. Xu Y, Liu Z, Liu L, Zhao C, Xiong F, Zhou C, et al. Neurospheres from rat adipose-derived stem cells could be induced into functional Schwann cell-like cells in vitro. BMC Neurosci. 2008; 9(1): 21.

32. Gaiba S, França LPd, França JPd, Ferreira LM. Characterization of human adipose-derived stem cells. Acta Cir Bras. 2012; 27(7): 471-6.

33. Baer PC, Geiger H. Adipose-derived mesenchymal stromal/stem cells: tissue localization, characterization, and heterogeneity. Stem cells Int. 2012; 2012: 812693.

34. Go HS, Seo JE, Kim KC, Han SM, Kim P, Kang YS, et al. Valproic acid inhibits neural progenitor cell death by activation of NF-B signaling pathway and up-regulation of Bcl-XL. J Biomed Sci. 2011; 18(1): 48.

35. Yang J, Yan Y, Ciric B, Yu S, Guan Y, Xu H, et al. Evaluation of bone marrow-and brain-derived neural stem cells in therapy of central nervous system autoimmunity. Am J Pathol. 2010; 177(4): 1989-2001.

36. Lee SH, Jeyapalan JN, Appleby V, Noor M, Azri D, Sottile $\mathrm{V}$, et al. Dynamic methylation and expression of Oct4 in early neural stem cells. J Anat. 2010; 217(3): 203-13. 